\title{
Portland Cement Partially Replaced by Blast Furnace Slag and Multi-Walled Carbon Nanotubes: Effect on Corrosion Resistance of Carbon Steel Reinforcement in $3 \% \mathrm{NaCl}$
}

\author{
Yang Ming ${ }^{1,2,3}$, Ping Chen ${ }^{1,2,3, *}$, Ling $\operatorname{Li}^{1,2,3^{*}}$, Cheng $H u^{1,2,3}$ \\ ${ }^{1}$ Guangxi Key Laboratory of New Energy and Building Energy Saving, Guilin 541004, China; \\ ${ }^{2}$ College of Civil and Architecture Engineering, Guilin University of Technology, Guilin 541004, \\ China; \\ ${ }^{3}$ Guangxi Beibu Gulf Engineering Research Center for Green Marine Materials, Guilin 541004, China; \\ *E-mail: chenping8383@188.com and aileen540220@ sina.com
}

doi: $10.20964 / 2020.09 .35$

Received: 13 May 2020 / Accepted: 30 June 2020 / Published: 10 August 2020

\begin{abstract}
A partial replacement for Portland cement (PC) through supplementary cementitious materials is an alternative technique to reduce carbon steel corrosion in reinforced concrete under exposure to marine environment. Here, the effect of blast furnace slag (BFS) and carbon nanotubes (CNTs) admixtures into PC on the electrochemical corrosion resistance of carbon steel reinforced concrete was assessed by electrochemical impedance spectroscopy (EIS) and polarization systems during immersion in 3.5 $\mathrm{wt} \% \mathrm{NaCl}$ media. The higher compressive strength was observed for BFS-CNT sample which can be attributed to the pozzolanic reaction of BFS filler, the formation of denser microstructure and acceleration of the hydration process. The polarization results show that the concrete samples containing CNTs admixture had a lower value of corrosion current density and corrosion rate revealing the superior performance than the other samples. The EIS measurements indicated that BFS-CNT sample was most effective for enhancing the corrosion resistance of the steel rebar due to the decrease of water absorptivity and chloride ion permeability.
\end{abstract}

Keywords: Carbon nanotubes; Blast furnace slag; Portland cement; Corrosion resistance; Electrochemical characterizations

\section{FULL TEXT}

(C) 2020 The Authors. Published by ESG (www.electrochemsci.org). This article is an open access article distributed under the terms and conditions of the Creative Commons Attribution license (http://creativecommons.org/licenses/by/4.0/). 